\title{
Through-Thickness Compression Testing of Commercially Pure (Grade II) Titanium Thin Sheet to Large Strains
}

\author{
K. K. Smith and M. E. Kassner \\ Department of Chemical Engineering and Materials Science, University of Southern California, Los Angeles, CA 90089, USA \\ Correspondence should be addressed to M. E. Kassner; kassner@usc.edu
}

Received 1 July 2016; Accepted 30 August 2016

Academic Editor: Menahem Bamberger

Copyright ( 92016 K. K. Smith and M. E. Kassner. This is an open access article distributed under the Creative Commons Attribution License, which permits unrestricted use, distribution, and reproduction in any medium, provided the original work is properly cited.

\begin{abstract}
This study examined the through-thickness ( $z$-direction) compressive stress versus strain behavior of $99.76 \%$ commercially pure (grade II) titanium sheet with relatively small grain size. The current study complemented earlier compression studies by examining a very thin $(1.60 \mathrm{~mm})$ sheet and deforming the Ti by successive compression tests to relatively large strains. The low aspect ratio, of the compression specimens extracted from the sheet, led to frictional effects that can create high triaxial stresses complicating the uniaxial stress versus strain behavior analysis. Nonetheless, reasonable estimates were made of the through-thickness large-strain behavior of a commercially pure (grade II) thin Ti sheet to relatively large true strains of about 1.0.
\end{abstract}

\section{Introduction}

The purpose of this study was to assess the through-thickness compressive mechanical behavior of a thin commercial purity titanium sheet to relatively large strains. Such sheet is often used in metal forming operations. Several studies have previously assessed the mechanical properties of commercially pure titanium in compression, usually as an extruded rod or sheet. Sheet thicknesses were much larger than the current study and strains were relatively small in comparison to the current study as well. Adiabatic heating may have been an additional issue complicating the stress versus strain behavior in these earlier studies. Large-strain studies of metals reveal substantially different hardening behaviors in tension, compression, and torsion, largely due to different textural evolutions (differences in average $M$ or Taylor factors) [1]. The focus of the current study was large-strain deformation in compression. Earlier studies are reviewed first below.

Compression experiments on commercially pure (grade I) Ti performed by Battaini et al. [2] focused on orientation effects. Five differently oriented samples were prepared from a $99.49 \%$ pure hot-rolled plate with a $10 \mathrm{~mm}$ thickness. However, only samples with the compression axis parallel to the plate normal (denoted as NT and NR) are discussed in the present paper. The notation given to the samples are defined by the compression direction (1st letter) and the extension direction (2nd letter), where " $N$ " denotes the normal direction, " $\mathrm{R}$ " denotes the rolling direction, and " $\mathrm{T}$ " denotes the transverse direction. The stress-strain curves for NT and NR are illustrated in Figure 1 and were deformed at a strain rate $(\dot{\varepsilon})$ of $0.1 \mathrm{~s}^{-1}$. It is unclear whether the samples were annealed prior to testing. A grain size of $22 \mu \mathrm{m}$ was reported. No lubrication was specified. Their orthorhombic samples had dimensions of 8 -mm length, $12-\mathrm{mm}$ width, and $5.95 \mathrm{~mm}$ height. In order to be consistent with the aspect ratio annotation in the present study that will be discussed later, the above dimensions can be translated to an aspect ratio annotation of $\mathrm{N} /(\overline{T R})$, where $(\overline{T R})$ denotes the average of the length $(T)$ and width $(R)$. Therefore, samples NR and NT have an aspect ratio of 0.595 (rounded to 0.60 in Figure 1).

Specimens deformed in the normal direction showed the highest yield stress. A lower yield and lower flow stresses were observed along the axis parallel to the rolling direction. Twinning was also observed in their deformed specimens as confirmed with EBSD.

The specimens were only deformed to a modest strain of about 0.12 . It should also be mentioned that throughout this paper both grade I and grade II titanium are discussed. The 


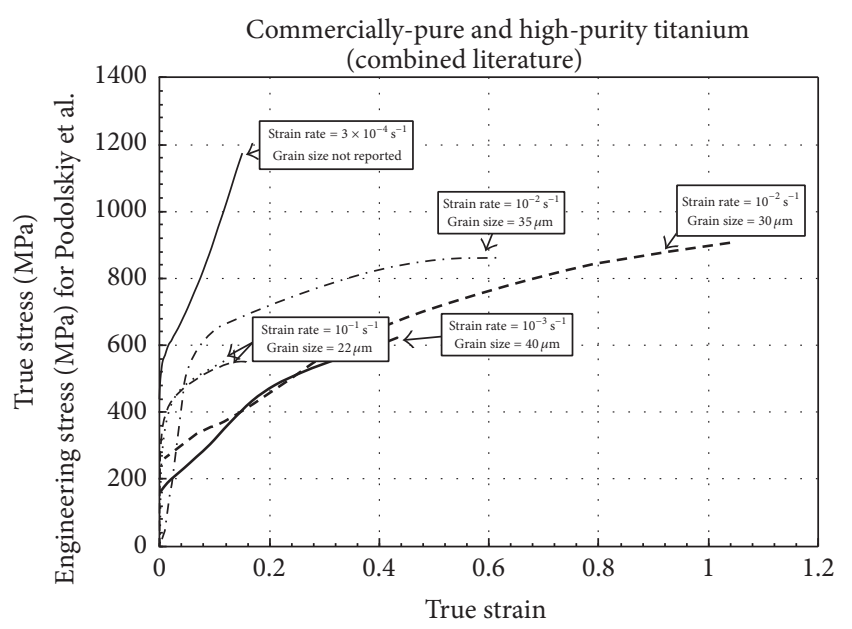

Engineering strain for Podolskiy et al.

- . 99.60\% CP-Ti (Long et al.), $t=$ not given, $t / d=1.50$

- 99.52\% CP-II Ti (Podolskiy et al.), $t=35 \mathrm{~mm}, t / d=3.50$

- - 99.49\% CP-Ti [NR] (Battaini et al.), $t=8 \mathrm{~mm}, t: w: d=0.75$

… 99.49\% CP-Ti [NT] (Battaini et al.), $t=8 \mathrm{~mm}, t: w: d=0.75$

- - $99.998 \%$ high-purity Ti (Salem et al.), dimensions not given

- $99.99 \%$ high-purity Ti (Nemat-Nasser et al.), $t=4.8 \mathrm{~mm}$, $t / d=1.00$

FIGURE 1: Summary graph of the compression stress versus strain behavior discussed in the earlier figures.

difference between the two is directly related to low $(\leq 0.18 \%)$ and standard $(\leq 0.25 \%)$ oxygen content, respectively, according to the ASTM B265 Standards. Grade II generally has a higher yield strength.

Podolskiy et al. performed compression tests on $99.52 \%$ commercially pure (grade II) tetragonal-shaped titanium [3] specimens deformed at $\dot{\varepsilon}=3 \times 10^{-4} \mathrm{~s}^{-1}$. The samples were cut from an extruded rod and loaded parallel to the extrusion direction. Samples were not specified as having been annealed but were dipped in liquid nitrogen immediately following machining of individual samples. The dimensions were reported as $1.8 \mathrm{~mm} \times 1.8 \mathrm{~mm} \times 3.5 \mathrm{~mm}$ (length $\times$ width $\times$ height) with an aspect ratio of 1.94. An engineering stressstrain curve is shown for the coarse-grained (CG) sample. Podolskiy et al. used the CG notation to define a sample that was not subjected to severe plastic deformation (SPD) through ECAP. Though an initial grain size is not reported, it can be presumed that a CG sample is coarse as compared to the ultrafine grained (UFG) sized samples subjected to SPD. The ambient temperature Ti data is illustrated in Figure 1. A noticeable upward parabolic shape characteristic of an increasing hardening rate $(d \sigma / d \varepsilon)$ is observed, which is unexpected. As discussed more subsequently, a surprisingly high strain-hardening rate was observed at uncharacteristically low strain levels around 0.15. No lubrication was stated to have been used in this study. Perhaps the rapid increase in stress over a small strain interval is a result of frictional effects leading to high triaxiality. This topic is discussed more in the following subsection. The increase in stress could appear exaggerated when plotted as engineering stress-strain rather than true stress-strain; however, the parabolic shape would still be apparent even if the conversion is taken into account. A rather high $0.2 \%$ offset yield stress was observed at $500 \mathrm{MPa}$. This may be an indication of prestraining from the prior extrusion in addition to any frictional effects.

Coarse-grained (CG) and ultrafine grained (UFG) titanium were compared at cryogenic, ambient, and elevated temperatures by Long et al. [4]. A 99.60\% pure Ti cylindrical billet with an initial diameter of $25 \mathrm{~mm}$ and length equal to $100 \mathrm{~mm}$ was used as the starting material. Grain sizes for the CG-Ti and UFG-Ti are $30 \mu \mathrm{m}$ and $250 \mathrm{~nm}$, respectively. The CG-Ti samples were tested from extruded rod, where the UFG-Ti was additionally refined by ECAP. The sample dimensions were tetragonal and had length: width: height ratios equal to $1: 1: 1.5$ (an aspect ratio of 1.50). Specific sample dimensions were not reported. The ambient temperature CGTi data is reported in Figure 1. A large amount of strainsoftening was observed in the UFG-Ti in contrast to the CGTi (UFG-Ti plot is not shown for comparison due to lack of relevance to the present study). A lower yield stress was observed in the CG-Ti as opposed to the UFG-Ti. Relatively large strains of 0.55 were achieved. A $0.2 \%$ offset yield strength equal to $530 \mathrm{MPa}$ for the CG-Ti was reported.

Nemat-Nasser et al. [5] performed compression studies on $99.99 \%$ high-purity titanium at temperatures ranging from $77 \mathrm{~K}$ to $1000 \mathrm{~K}$ under lower $\left(10^{-3}-10^{-1} \mathrm{~s}^{-1}\right)$ and dynamic $\left(2200-8000 \mathrm{~s}^{-1}\right)$ strain-rate conditions. Only experiments done at strain rates $(\dot{\varepsilon})$ of $10^{-1}$ and $10^{-3} \mathrm{~s}^{-1}$ at ambient temperature are discussed here. Cylindrical samples with an aspect ratio of 1.0 were annealed at $704^{\circ} \mathrm{C}$ before testing. The sample height was $4.8 \mathrm{~mm}$ and the average grain size after annealing was $40 \mu \mathrm{m}$. The compression axis was parallel to the extrusion direction of the extruded rod. Strains up to 0.43 and 0.41 were achieved for $\dot{\varepsilon}=10^{-3} \mathrm{~s}^{-1}$ and $\dot{\varepsilon}=10^{-1} \mathrm{~s}^{-1}$, respectively, at $296 \mathrm{~K}$. The behavior is illustrated in Figure 1.

Mechanical twins were observed in this study as well. This data suggests a strain-rate sensitivity $(m)$ between 0.027 and 0.044 [5]. The strain-rate sensitivity is defined by the following expression:

$$
m=\left(\frac{\partial \ln (\sigma)}{\partial \ln (\dot{\varepsilon})}\right)_{s, T},
$$

where $s$ denotes a constant dislocation structure and $T$ is temperature. The lower strain rate shows a lower yield stress as expected.

Strains greater than 1.0 were achieved by Salem et al. [6] in $99.998 \%$ high-purity titanium. Relubrication, with high-pressure grease and Teflon sheets, was performed every $0.3 \sim 0.4$ strains. This was intended to reduce barreling and allow for higher strain accumulation by precluding excessive triaxiality. Samples were machined from a plate of unspecified thickness and were annealed for 1 hour at $800^{\circ} \mathrm{C}$ and then oilquenched. The behavior of this material is shown in Figure 1.

The deformed samples were prepared for TEM in order to observe the onset of twinning and Salem et al. report this as the primary mode of deformation for high-purity $\alpha$-titanium. Twins were not observed until about 0.05 strains, resulting in an increased strain-hardening rate. 
Figure 1 is a composite of the previously discussed literature studies [2-6]. The lower two reported yield stresses are the higher purity compression experiments. The highest yield stress appears to represent a prestrained, unannealed (and possibly unlubricated) specimen. All, but one, of the studies are for strains of 0.12 to 0.55 . There appears to be significant variation in the yield stress of the specimens, even with three studies of comparable purity. Additionally, the tests are at higher strain rates where adiabatic heating (particularly in CP-Ti) can occur and obfuscate the isothermal mechanical behavior [7]. The grain sizes appear to be generally similar.

Again, the goal of the present study was to assess the true stress versus true strain behavior of thin-sheet commercially pure (grade II) titanium at ambient temperature. As noted in the previous literature studies, titanium compression tests were performed on specimens that, in all cases, were $8 \mathrm{~mm}$ or greater in height for commercial purity (about $5 \mathrm{~mm}$ for high purity). Furthermore, as mentioned previously, the total strains were only about 0.12 to 0.55 (with only one exception). As discussed subsequently, these are relatively thick. Also, the strains are typically much larger for metal forming of thin sheet and the sheet thicknesses are often below $2 \mathrm{~mm}$. Strain rates for the literature studies discussed were also typically relatively high at $10^{-2} \mathrm{~s}^{-1}$ to $10^{-1} \mathrm{~s}^{-1}$ which, as mentioned earlier, can be associated with adiabatic heating, particularly in higher strength $\mathrm{CP}-\mathrm{Ti}$ as compared to high-purity $\mathrm{Ti}$, and temperature rises in the specimen can occur. Thus, this study attempted to characterize the large-strain stress versus strain behavior of very thin commercial purity Ti sheet in the through-thickness direction at strain rates of $10^{-4} \mathrm{~s}^{-1}$ where adiabatic heating is not expected and isothermal behavior can be characterized. Higher strains than observed in the literature would be attempted. This would represent new data in the literature, but this work had several experimental complications, as discussed subsequently.

First, barreling and frictional stresses are a major complication in all compression testing. Compression experiments especially on sheet metals with an initially low height, as in this study, encounter frictional effects which can significantly complicate the assessment of the uniaxial stress versus strain behavior. Schroeder and Webster [8] provided an analysis of the frictional effects in compression testing and estimated a correction factor for frictional effects to the observed flow stress in a material. Schroeder and Webster's correction factor is used in the analysis of the present work. Barreling is typical of a sample that has a very small aspect ratio $(l / d \ll 0.8$, i.e., $l \ll d)[9]$, where "l" is the specimen height and " $d$ " is the specimen diameter. Barreling is a result of excess friction in which the material is restricted from moving uniformly. The sample becomes pinned at the specimen surfaces in contact with the moving platens during testing. This creates a triaxial state of stress which creates an observed flow stress that is higher than that which would be observed for pure uniaxial loading. One way to mitigate the frictional effects is to use lubricants on both surfaces of the sample before testing. Schroeder and Webster [8] suggested that the triaxiality leads to a necessary correction to the observed load for deformation to the equivalent uniaxial stress for plasticity in the absence of friction. This requires knowledge of $l / d$ and the frictional coefficient. Small $l / d$ as in the present study tends to lead to larger corrections. Furthermore, during testing, the frictional coefficient may change (increase) leading to increasing triaxiality resulting from the barreling. This prescribes a repeating sequence of unloading and reloading with new lubrication of the specimen and platen surfaces after varying incremental strains. It should be noted that the first four specimens (samples 1-4) were not finely polished at the surface prior to compression testing and were tested "as machined." The last three specimens (samples 7, 8, and 10) were finely polished to $0.05 \mu \mathrm{m}$ alumina. Additionally, the compression platens were polished before every test and between testing phases, with a new application of lubricant.

\section{Experimental Procedure}

The commercially pure grade II titanium (CP-II Ti) material used in this was supplied by UniTi Titanium LLC in Coraopolis, PA. The chemical composition, shown in Table 1, was performed using inductively coupled plasma atomic emission spectroscopy (IC-AES). This analysis was done by Westmoreland Mechanical Test \& Research, Inc., WMT\&R, in accordance with ASTM E2371-13.

The titanium sheet was $1.60 \mathrm{~mm}$ in thickness, much thinner than that of sheet of the previously discussed studies. It was provided as annealed and the average grain size was about $14 \mu \mathrm{m}$. The average grain diameter was calculated using the average grain intercept method. Micrographs of the normal, rolling, and transverses faces, respectively, are illustrated in Figure 2.

The titanium sheet was sent to Able Wire EDM Inc., in Brea, CA, where electrical discharge machining (EDM) was used to cut the sheet into smaller cylindrical samples. All samples were spark cut to a diameter of $3 \mathrm{~mm}$. There were many samples made but only seven of them were compression tested and named sequentially as samples $1,2,3,4,7,8$, and 10. As discussed in the Introduction, some of the specimens were remachined after strains of approximately 0.4-0.5. Remachining decreased the diameter allowing the aspect ratio to decrease and decrease the triaxiality. The cylindrical samples were remachined using 2 different methods: (1) ultrasonic disk cutter and (2) "conventional" lathe machining in a machine shop.

2.1. Ultrasonic Disk Cutter. A Model 170 Ultrasonic Disk Cutter made by E.A. Fischione Instruments Inc. was used to cut samples 3, 4, 7, and 8 after deformation (subsequent to the initial EDM cutting). A titanium cylindrical tube is used to effectively cut through a sample with minimal mechanical and thermal damage. This cuts disks of the size of the inner diameter of the drill. Two cylinders with inner diameter sizes of $2 \mathrm{~mm}$ and $3 \mathrm{~mm}$ were available. The $2 \mathrm{~mm}$ cylindrical drill was used to remachine samples $3,4,7$, and 10 . The $3 \mathrm{~mm}$ cylindrical drill was used to remachine sample 8 . The ultrasonic cutter uses a high oscillating frequency $(\sim 26 \mathrm{kHz})$ with an abrasive 800 -grit silicon carbide ( $\mathrm{SiC}$ ) slurry. 
TABLE 1: Chemical composition of CP-II Ti of this study.

\begin{tabular}{lcccccc}
\hline & \multicolumn{4}{c}{ Chemical composition of the CP-II titanium used in this study } & & \\
Element & Carbon & Oxygen & Nitrogen & Hydrogen & Iron & Ti (balance) \\
\hline Weight (in \%) & $0.01 \%$ & $0.13 \%$ & $0.002 \%$ & $0.0018 \%$ & $0.09 \%$ & $\mathbf{9 9 . 7 6 \%}$ \\
\hline
\end{tabular}

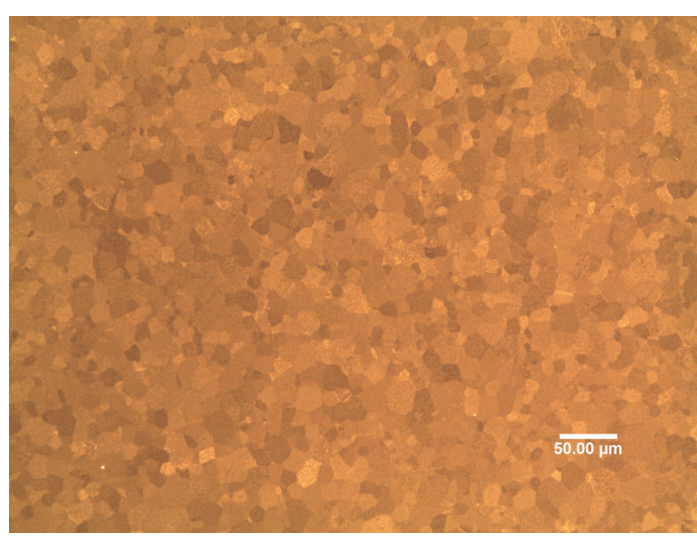

(a)

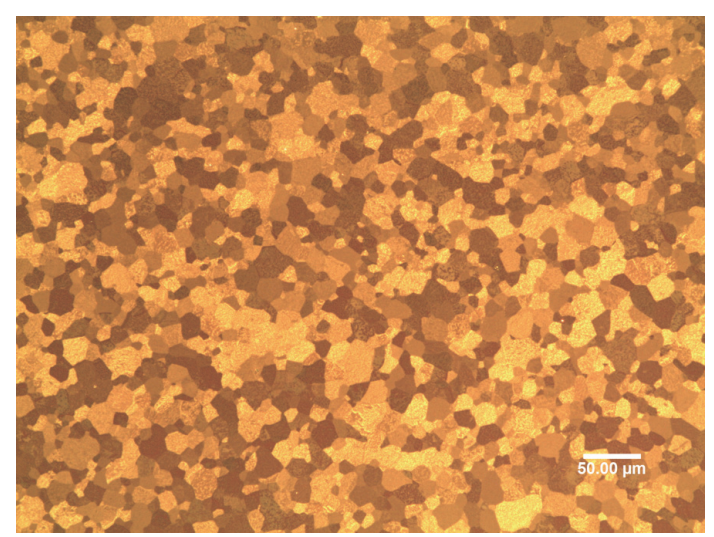

(b)

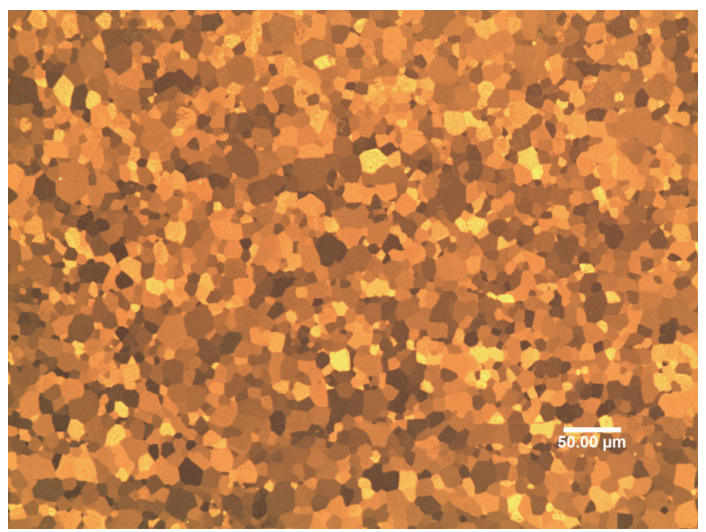

(c)

Figure 2: Optical micrographs of the plane (a) normal, (b) rolling, and (c) transverse sections of the annealed titanium sheet. Micrographs were provided by nanoPrecision in El Segundo, CA.

2.2. Conventional Lathe Machining. The machining process involved using a conventional lathe to cut the sample circumference in $0.005 \mathrm{~mm}$ increments. Cold air was kept at a steady flow over both the specimen and specimen holder to avoid any thermal heating that would affect the sample microstructure during the cutting process.

2.3. Compression Specimen Surface Polishing. Samples 7, 8, and 10 surfaces in contact with the compression platens were polished to a fine finish to attempt minimum friction between the compression platens. Due to the small size, the titanium samples were mounted in quick-set acrylic for polishing. Two sequential mechanical polishing techniques were used: silicon carbide ( $\mathrm{SiC}$ ) grit paper followed by a diamond/alumina suspension slurry. The III Wet Polisher/Grinder used SiC grades from 320 to 1200 CarbiMet SiC grit paper discs from Buehler. Cool deionized water was continuously flowing to keep the grit paper wet and the sample cool. Buehler
MetaDi ${ }^{\mathrm{TM}}$ monocrystalline diamond suspensions were subsequently used on a Struers LaboPol-2 $203 \mathrm{~mm}$ diameter magnetic polishing wheel. The diamond slurries ranged from $9 \mu \mathrm{m}$ to $0.25 \mu \mathrm{m}$. The last step used $0.05 \mu \mathrm{m}$ alumina paste. Between compression testing phases, these samples were repolished with $1 \mu \mathrm{m}$ and $0.25 \mu \mathrm{m}$ alumina polish and relubricated.

2.4. Mechanical Testing. Compression testing utilized an Instron ${ }^{\circledR} 5585 \mathrm{H}$ Series Floor Model Testing System with a $\pm 250 \mathrm{kN}$ load cell. Bluehill ${ }^{\circledR}$ Software was used for collecting the data. An OEM ${ }^{\circledR}$ Tools 25025 26-blade Master Feeler Gauge was used to measure the space between platens to test parallelism of the compression platens. A machine compliance test was done before each test to ensure that the specimen strain was accurately assessed.

Seven samples were tested (i.e., 1, 2, 3, 4, 7, 8, and 10). Three different types of lubrication were used during compression 
TABle 2: (a) Friction coefficients $[13,14,23,24]$ of the lubricants used in the present study. The graphite and $\mathrm{MoS}_{2}$ aerosol lubricants were generously sprayed on the compression platens before testing. (b) Lubricants used for each sample. In the case of the $\mathrm{MoS}_{2}$ and Teflon combination, the Teflon was placed on the upper and lower compression platens first and then the $\mathrm{MoS}_{2}$ was generously applied to the top of the Teflon.

(a)

\begin{tabular}{lcc}
\hline Lubricant & Form of lubricant & Friction coefficient $(\mu)$ \\
\hline $\begin{array}{l}\text { Graphite } \\
\text { Molybdenum }\end{array}$ & Dry aerosol & $0.123[23]$ \\
sulfide $\left(\mathrm{MoS}_{2}\right)$ & Dry aerosol & 0.03 or $0.23[13,14]$ \\
PTFE Teflon & $0.0762 \mathrm{~mm}$ thick paper & $0.05-0.08[24]$ \\
\hline
\end{tabular}

(b)

\begin{tabular}{lc}
\hline Sample & Lubricant \\
\hline Sample 1 & Graphite \\
Sample 2 & $\mathrm{MoS}_{2}$ \\
Sample 3 & $\mathrm{MoS}_{2}$ \\
Sample 4 & $\mathrm{MoS}_{2}$ \\
Sample 7 & $\mathrm{MoS}_{2}$ and Teflon \\
Sample 8 & $\mathrm{MoS}_{2}$ and Teflon \\
Sample 10 & $\mathrm{MoS}_{2}$ and Teflon \\
\hline
\end{tabular}

testing to eliminate as much friction as possible: (1) B'laster ${ }^{\circledR}$ Graphite Dry Lubrication, (2) CRC ${ }^{\circledR}$ Industrial Inc. dry Moly Lube, molybdenum sulfide $\left(\mathrm{MoS}_{2}\right)$, and (3) PTFE Teflon paper (thickness $=0.0762 \mathrm{~mm}$ ) from McMaster-Carr ${ }^{\circledR}$ Supply Company. The frictional coefficients for each lubrication and which lubrication was used on each sample are listed in Tables 2(a) and 2(b).

2.5. Barreling. Corrections to the (load/area) versus strain due to friction (leading to barreling) utilized Schroeder and Webster's equation [8]:

$$
\sigma=\frac{\left(\sigma_{m} / 2\right)(\mu d / l)^{2}}{\exp (\mu d / l)-(\mu d / l)-1},
$$

where $\sigma_{m}$ denotes the measured flow stress (load/area), $\mu$ is the lubricant friction coefficient, $d$ is the sample diameter, $l$ is the sample height (length), and $\sigma$ is the resulting corrected flow stress. This equation assumes that the friction coefficients $(\mu)$ are constant with strain; however, this may not be the case. In fact, specimens were unloaded and reloaded after reapplying lubricant as the friction may actually increase with strain during a loading phase.

\section{Results and Discussion}

The true stress versus true strain behaviors are illustrated in Figures 3(a)-3(g) for all samples. The term "phase" in the accompanying tables refers to the (re)loading stages. A best fit line is used to describe the stress versus strain behavior after barreling (from friction) corrections. Note that remachining was performed so as to keep the $t / d$ ratios as low as possible without cutting the specimen to impractical testing diameters. Samples 1, 2, 3, and 4 surfaces were not polished before initial testing or reloading. New lubrication was applied before each compression phase. Only samples 7, 8, and 10 were repolished prior to each reload to minimize frictional effects. As will be discussed later, polished specimens did not necessarily produce better stress versus strain curves than specimens with unpolished surfaces.

It should be mentioned that texture characterization was not considered to effect the mechanical properties. Previous works $[1,2,10-12]$ on thicker sheets have been done to confirm that when working in a preferred loading axis, the crystal will develop a preferred grain texture.

The coefficient of friction of $\mathrm{MoSi}_{2}$ is listed in some sources as just 0.03 [13] but the manufacturer of the spray utilized in this work listed the frictional coefficient as 0.23 [14]. Both values were considered in sample 2 plot.

The results of sample 4 indicate an anomalous drop in flow stress on reapplication of loading at a strain of about 0.6. The source of this anomaly is unknown. However, the large "drop" in this specimen and the observed (smaller) drops and other anomalous behaviors in other tests may reflect the complications associated with very low aspect ratio compression tests. One of the authors of this study performed earlier compression tests on CP-Al [15] and maintained a 1.5 aspect ratio and found none of the complications found in this work using nearly identical testing procedures.

All of the tested samples are graphically summarized in Figure 4. The curves shown represent each samples' best fit line. The dashed pattern of each curve denotes the frictional coefficient belonging to the lubrication used for that sample, and the average strain rate for each sample is also noted. Because both frictional coefficients are being considered for $\mathrm{MoS}_{2}$, the red and green curves represent the average stressstrain curve over all samples using $\mu=0.03,0.05,0.123$ and $\mu=0.05,0.123,0.23$, respectively.

The complication of Figure 5 is that the data of the various studies were obtained at different strain rates. Ideally, comparisons are made at a fixed strain rate. Thus, the data of Figure 5 was normalized to a strain rate equal to $10^{-1} \mathrm{~s}^{-1}$ (the maximum of any study) using a conversion procedure based on an average strain-rate sensitivity exponent $(m)$. Several studies [16-21] measured the room temperature strain-rate sensitivity of Ti alloys and determined $m$-values ranging from 0.007 to 0.04 for CP-Ti. The average of 0.024 is somewhat lower than the average $m$-value reported in the Nemat-Nasser et al. study [5] of Figure 1 which suggested a value of about 0.035 . The higher value may reflect a lack of a fixed structure at a fixed strain, thus artificially increasing $m$ in this case. Figure 6 is plotted using an $m$-value of 0.024 and all stress versus strain curves of the various studies are normalized to a strain rate of $0.1 \mathrm{~s}^{-1}$.

It can be observed that the behavior in the current study appears similar to earlier work for the cases of similar purity, annealed $\mathrm{Ti}$. The exception to the similarity appears to be that our thin sheet has somewhat higher flow stresses after the strain-rate correction. The origin of the relative increase in normalized stress is unclear. 
Sample 1

Yield stress $=395 \mathrm{MPa}$

Initially cut with EDM; dry graphite powder used for lubrication

(* indicates machining done after that given compression phase)

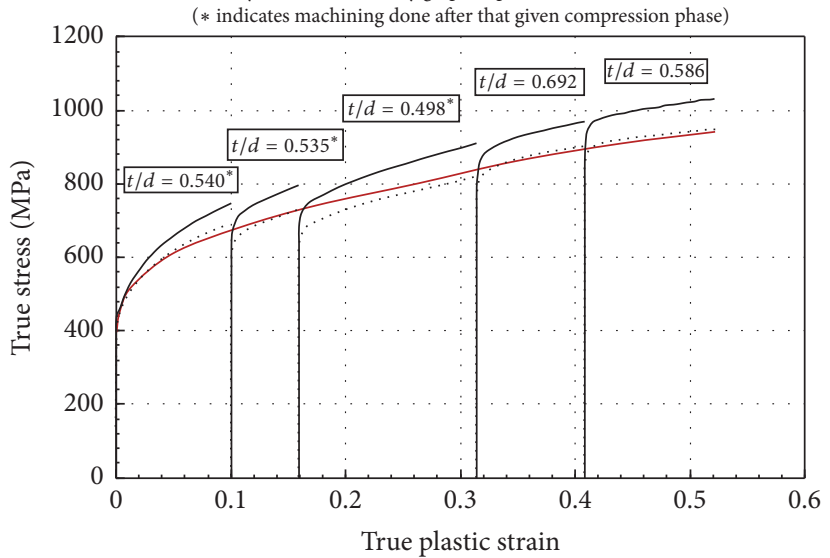

— Best fit line

.... Corrected flow stress $(\mu=0.123)$

_ True stress (MPa), no correction

Sample 1

\begin{tabular}{cccccccccc}
\hline & $\begin{array}{c}t_{o} \\
(\mathrm{~mm})\end{array}$ & $\begin{array}{c}t_{f} \\
(\mathrm{~mm})\end{array}$ & $\begin{array}{c}d_{o} \\
(\mathrm{~mm})\end{array}$ & $\begin{array}{c}d_{f} \\
(\mathrm{~mm})\end{array}$ & $t_{o} / d_{o}$ & $t_{f} / d_{f}$ & $\begin{array}{c}\text { Volume } \\
\left(\mathrm{mm}^{3}\right)\end{array}$ & $\begin{array}{c}\text { Crosshead } \\
\text { speed } \\
(\mathrm{mm} / \mathrm{min})\end{array}$ & $\begin{array}{c}\text { Strain rate } \\
\left(\mathrm{s}^{-1}\right)\end{array}$ \\
\hline $1^{*}$ & 1.61 & 1.43 & 2.98 & 3.16 & 0.54 & 0.45 & 11.23 & 0.003 & $3.11 \times 10^{-5}$ \\
$2^{*}$ & 1.53 & 1.36 & 2.86 & 3.03 & 0.53 & 0.45 & 9.83 & 0.003 & $3.27 \times 10^{-5}$ \\
$3^{*}$ & 1.43 & 1.16 & 2.87 & 3.15 & 0.50 & 0.37 & 9.25 & 0.003 & $3.50 \times 10^{-5}$ \\
4 & 1.19 & 1.06 & 1.72 & 1.80 & 0.69 & 0.59 & 2.76 & 0.003 & $4.20 \times 10^{-5}$ \\
5 & 1.04 & 0.94 & 1.78 & 1.93 & 0.59 & 0.48 & 2.76 & 0.003 & $4.81 \times 10^{-5}$ \\
\hline
\end{tabular}

(a)

Sample 3

Yield stress $\simeq 401 \mathrm{MPa}$

Initially cut with EDM

$\mathrm{MoS}_{2}$ aerosol used for lubrication

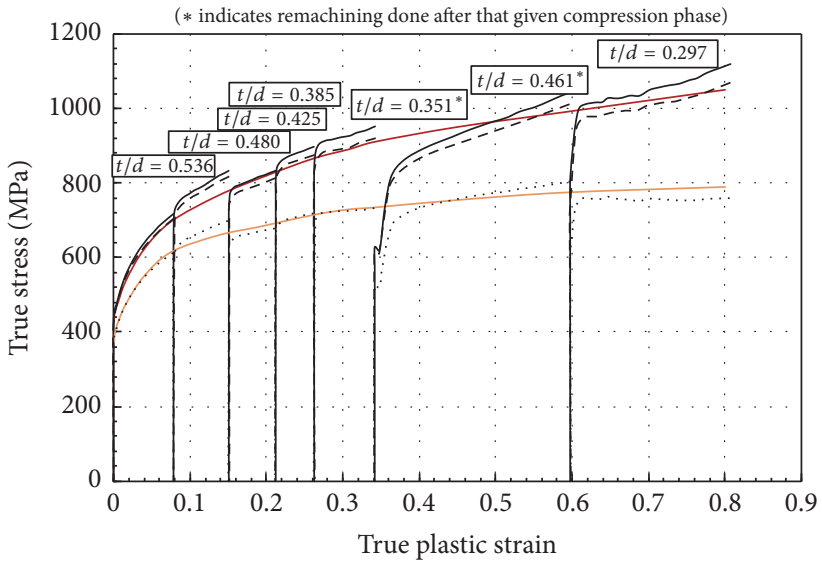

_ Best fit line (0.03)

- - - Corrected flow stress

Corrected flow stress $(\propto=0.03)$

$(\propto=0.23)$

_ Best fit line (0.23)

— True stress $(\mathrm{MPa})$, no correction

\begin{tabular}{lccccccccc}
\multicolumn{10}{c}{ Sample 3 } \\
\hline & $\begin{array}{c}t_{o} \\
(\mathrm{~mm})\end{array}$ & $\begin{array}{c}t_{f} \\
(\mathrm{~mm})\end{array}$ & $\begin{array}{c}d_{o} \\
(\mathrm{~mm})\end{array}$ & $\begin{array}{c}d_{f} \\
(\mathrm{~mm})\end{array}$ & $t_{o} / d_{o}$ & $t_{f} / d_{f}$ & $\begin{array}{c}\text { Volume } \\
\left(\mathrm{mm}^{3}\right)\end{array}$ & $\begin{array}{c}\text { Crosshead } \\
\text { speed } \\
(\mathrm{mm} / \mathrm{min})\end{array}$ & $\begin{array}{c}\text { Strain rate } \\
\left(\mathrm{s}^{-1}\right)\end{array}$ \\
\hline 1 & 1.6002 & 1.4860 & 2.9845 & 3.1370 & 0.5362 & 0.4737 & 11.1942 & 0.003 & $3.13 \times 10^{-5}$ \\
2 & 1.4860 & 1.3716 & 3.1370 & 3.2572 & 0.4737 & 0.4211 & 11.1942 & 0.003 & $3.37 \times 10^{-5}$ \\
3 & 1.3716 & 1.2827 & 3.2572 & 3.3655 & 0.4211 & 0.3811 & 11.1942 & 0.003 & $3.65 \times 10^{-5}$ \\
4 & 1.2827 & 1.2065 & 3.3655 & 3.4925 & 0.3811 & 0.3455 & 11.1942 & 0.003 & $3.90 \times 10^{-5}$ \\
$5^{*}$ & 1.2065 & 1.1050 & 3.4925 & 3.6070 & 0.3455 & 0.3063 & 11.1942 & 0.003 & $4.14 \times 10^{-5}$ \\
$6^{*}$ & 1.0600 & 0.7800 & 2.3000 & 2.6600 & 0.4608 & 0.2932 & 4.4043 & 0.0064 & $1.00 \times 10^{-4}$ \\
7 & 0.7900 & 0.6100 & 2.6600 & 3.1000 & 0.2969 & 0.1968 & 4.4043 & 0.0047 & $1.00 \times 10^{-4}$ \\
\hline
\end{tabular}

(c)
Sample 2

Yield stress $\simeq 380 \mathrm{MPa}$

Initially cut with EDM; no remachining done to this sample $\mathrm{MoS}_{2}$ aerosol used for lubrication

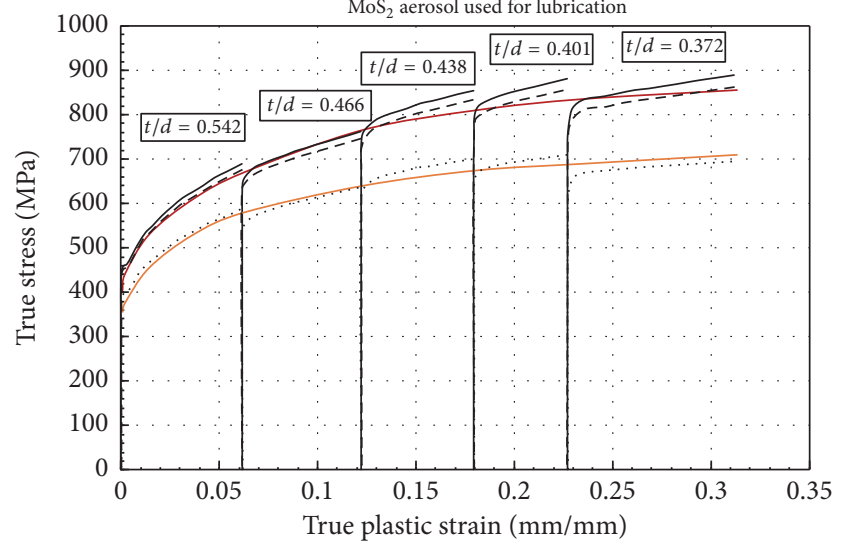

_ Best fit line (0.03)

Corrected flow stress $(\mu=0.23)$

Corrected flow stress $(\mu=0.03)$

- - - True stress (MPa), no correction

Sample 2

\begin{tabular}{lccccccccc}
\hline & $\begin{array}{c}t_{o} \\
(\mathrm{~mm})\end{array}$ & $\begin{array}{c}t_{f} \\
(\mathrm{~mm})\end{array}$ & $\begin{array}{c}d_{o} \\
(\mathrm{~mm})\end{array}$ & $\begin{array}{c}d_{f} \\
(\mathrm{~mm})\end{array}$ & $t_{o} / d_{o}$ & $t_{f} / d_{f}$ & $\begin{array}{c}\text { Volume } \\
\left(\mathrm{mm}^{3}\right)\end{array}$ & $\begin{array}{c}\text { Crosshead } \\
\text { speed } \\
(\mathrm{mm} / \mathrm{min})\end{array}$ & $\begin{array}{c}\text { Strain rate } \\
\left(\mathrm{s}^{-1}\right)\end{array}$ \\
\hline 1 & 1.6256 & 1.4986 & 2.9972 & 3.1242 & 0.5424 & 0.4797 & 11.4689 & 0.003 & $3.08 \times 10^{-5}$ \\
2 & 1.4986 & 1.4097 & 3.1242 & 3.2258 & 0.4797 & 0.4370 & 11.4689 & 0.003 & $3.27 \times 10^{-5}$ \\
3 & 1.4097 & 1.3335 & 3.2258 & 3.3274 & 0.4370 & 0.4008 & 11.4689 & 0.003 & $3.55 \times 10^{-5}$ \\
4 & 1.3335 & 1.2700 & 3.3274 & 3.4160 & 0.4008 & 0.3718 & 11.4689 & 0.003 & $3.75 \times 10^{-5}$ \\
5 & 1.2700 & 1.1557 & 3.4160 & 3.5687 & 0.3718 & 0.3238 & 11.4689 & 0.003 & $3.94 \times 10^{-5}$ \\
\hline
\end{tabular}

(b)

Sample 4

Yield stress $\simeq 345 \mathrm{MPa}$

Initially cut with EDM; $\mathrm{MoS}_{2}$ aerosol used for lubrication

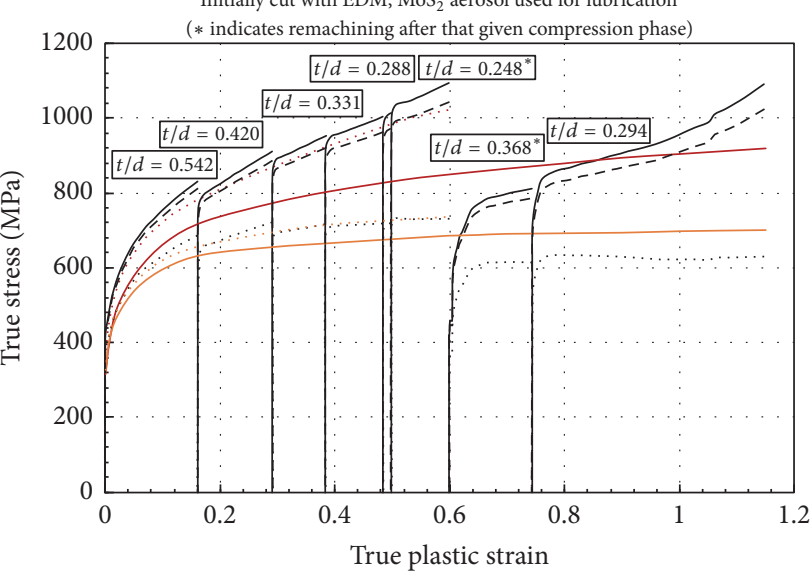

Best fit line (0.03) $(\varepsilon \leq 0.60) \quad$ …. Best fit line $(0.23)(\varepsilon \leq 0.60)$

True stress $(\mathrm{MPa})$, no correction — Best fit line (0.03) $(0 \leq \varepsilon \leq 1.15)$

- - - Corrected flow stress $(\propto=0.03) —$ Best fit line $(0.23)(0 \leq \varepsilon \leq 1.15)$

..... Corrected flow stress $(\propto=0.23)$

Sample 4

\begin{tabular}{lccccccccc}
\hline & $\begin{array}{c}t_{o} \\
(\mathrm{~mm})\end{array}$ & $\begin{array}{c}t_{f} \\
(\mathrm{~mm})\end{array}$ & $\begin{array}{c}d_{o} \\
(\mathrm{~mm})\end{array}$ & $\begin{array}{c}d_{f} \\
(\mathrm{~mm})\end{array}$ & $t_{o} / d_{o}$ & $t_{f} / d_{f}$ & $\begin{array}{c}\text { Volume } \\
\left(\mathrm{mm}^{3}\right)\end{array}$ & $\begin{array}{c}\text { Crosshead } \\
\text { speed } \\
(\mathrm{mm} / \mathrm{min})\end{array}$ & $\begin{array}{c}\text { Strain rate } \\
\left(\mathrm{s}^{-1}\right)\end{array}$ \\
\hline 1 & 1.6256 & 1.3716 & 2.9972 & 3.2893 & 0.5424 & 0.4169 & 11.4689 & 0.003 & $3.08 \times 10^{-5}$ \\
2 & 1.3716 & 1.1684 & 3.2893 & 3.5687 & 0.4169 & 0.3274 & 11.4689 & 0.003 & $3.65 \times 10^{-5}$ \\
3 & 1.1684 & 1.0668 & 3.5687 & 3.7084 & 0.3274 & 0.2877 & 11.4689 & 0.003 & $4.28 \times 10^{-5}$ \\
4 & 1.0668 & 0.9652 & 3.7084 & 3.9497 & 0.2877 & 0.2444 & 11.4689 & 0.003 & $4.69 \times 10^{-5}$ \\
5 & 0.9652 & 0.9525 & 3.9497 & 3.9525 & 0.2444 & 0.2410 & 11.4689 & 0.003 & $5.18 \times 10^{-5}$ \\
$6^{*}$ & 0.9525 & 0.8763 & 3.9525 & 4.1656 & 0.2410 & 0.2104 & 11.4689 & 0.003 & $5.25 \times 10^{-5}$ \\
$7^{*}$ & 0.8700 & 0.7500 & 2.3500 & 2.5750 & 0.3702 & 0.2913 & 3.7735 & 0.0052 & $1.00 \times 10^{-4}$ \\
8 & 0.7500 & 0.4500 & 2.5750 & 3.1800 & 0.2913 & 0.1415 & 3.7735 & 0.0045 & $1.00 \times 10^{-4}$ \\
\hline
\end{tabular}

(d)

Figure 3: Continued. 
Yield stress $=335 \mathrm{MPa}$

Initially cut with EDM

$\mathrm{MoS}_{2}$ aerosol and Teflon paper used for lubrication

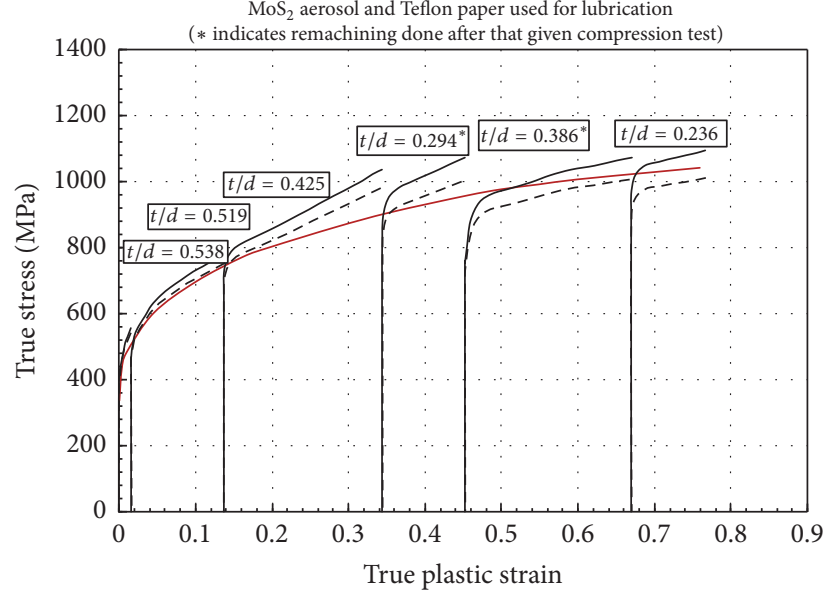

- Best fit line

- - Corrected flow stress $(\propto=0.05)$

_ True stress (MPa), no correction

Sample 7

\begin{tabular}{lccccccccc}
\hline & $\begin{array}{c}t_{o} \\
(\mathrm{~mm})\end{array}$ & $\begin{array}{c}t_{f} \\
(\mathrm{~mm})\end{array}$ & $\begin{array}{c}d_{o} \\
(\mathrm{~mm})\end{array}$ & $\begin{array}{c}d_{f} \\
(\mathrm{~mm})\end{array}$ & $t_{o} / d_{o}$ & $t_{f} / d_{f}$ & $\begin{array}{c}\text { Volume } \\
\left(\mathrm{mm}^{3}\right)\end{array}$ & $\begin{array}{c}\text { Crosshead } \\
\text { speed } \\
(\mathrm{mm} / \mathrm{min})\end{array}$ & $\begin{array}{c}\text { Strain rate } \\
\left(\mathrm{s}^{-1}\right)\end{array}$ \\
\hline 1 & 1.6000 & 1.5748 & 2.9720 & 3.0353 & 0.5384 & 0.5188 & 11.0993 & 0.0096 & $1.00 \times 10^{-4}$ \\
2 & 1.5748 & 1.3970 & 3.30353 & 3.2893 & 0.5188 & 0.4247 & 11.0993 & 0.0096 & $1.02 \times 10^{-4}$ \\
3 & 1.3970 & 1.0922 & 3.2893 & 3.7211 & 0.4247 & 0.2935 & 11.0993 & 0.0096 & $1.15 \times 10^{-4}$ \\
$4^{*}$ & 1.0922 & 0.9652 & 3.7211 & 4.0386 & 0.2935 & 0.2390 & 11.0993 & 0.0096 & $1.46 \times 10^{-4}$ \\
$5^{*}$ & 0.8800 & 0.6300 & 2.2800 & 2.7800 & 0.3860 & 0.2266 & 3.5929 & 0.0053 & $1.00 \times 10^{-4}$ \\
6 & 0.6400 & 0.5600 & 2.7100 & 2.9500 & 0.2362 & 0.1898 & 3.5929 & 0.0038 & $1.00 \times 10^{-4}$ \\
\hline
\end{tabular}

(e)

Sample 8

Yield stress $=351 \mathrm{MPa}$

Initially cut with EDM

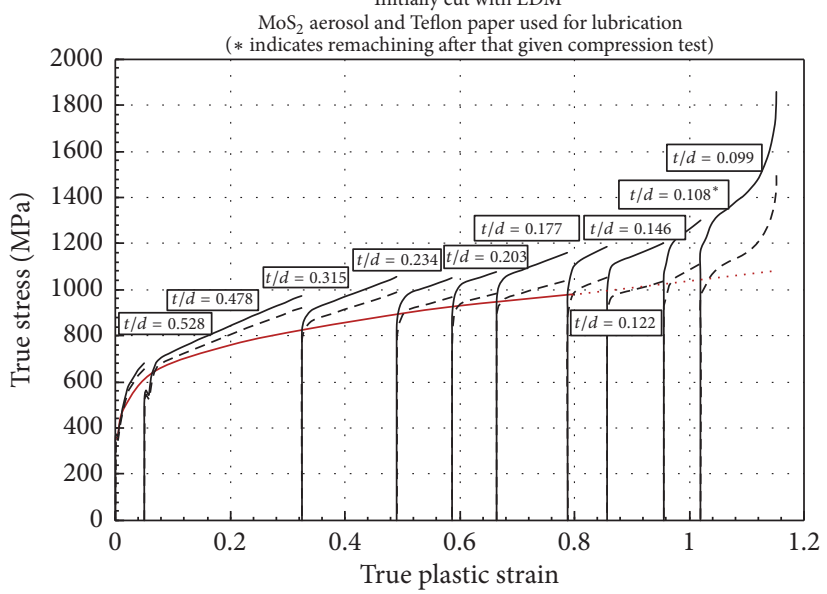

_ Best fit line __ True stress $(\mathrm{MPa})$, no correction

- - - Corrected flow stress $(\mu=0.05)$

\begin{tabular}{lcccccccccc}
\multicolumn{10}{c}{ Sample 8 } \\
\hline & $\begin{array}{c}t_{o} \\
(\mathrm{~mm})\end{array}$ & $\begin{array}{c}t_{f} \\
(\mathrm{~mm})\end{array}$ & $\begin{array}{c}d_{o} \\
(\mathrm{~mm})\end{array}$ & $\begin{array}{c}d_{f} \\
(\mathrm{~mm})\end{array}$ & $t_{o} / d_{o}$ & $t_{f} / d_{f}$ & $\begin{array}{c}\text { Volume } \\
\left(\mathrm{mm}^{3}\right)\end{array}$ & $\begin{array}{c}\text { Crosshead } \\
\text { speed } \\
(\mathrm{mm} / \mathrm{min})\end{array}$ & $\begin{array}{c}\text { Strain rate } \\
\left(\mathrm{s}^{-1}\right)\end{array}$ \\
\hline 1 & 1.5799 & 1.4935 & 2.9921 & 3.1242 & 0.5280 & 0.4780 & 11.1086 & 0.0096 & $1.01 \times 10^{-4}$ \\
2 & 1.4935 & 1.1406 & 3.1242 & 3.6169 & 0.4780 & 0.3153 & 11.1086 & 0.0096 & $1.07 \times 10^{-4}$ \\
3 & 1.1406 & 0.9449 & 3.6169 & 4.0386 & 0.3153 & 0.2339 & 11.1086 & 0.0096 & $1.15 \times 10^{-4}$ \\
4 & 0.9449 & 0.8636 & 4.0386 & 4.2469 & 0.2339 & 0.2033 & 11.1086 & 0.0096 & $1.69 \times 10^{-4}$ \\
5 & 0.8636 & 0.8001 & 4.2469 & 4.5187 & 0.2033 & 0.1770 & 11.1086 & 0.0096 & $1.85 \times 10^{-4}$ \\
6 & 0.8001 & 0.6985 & 4.5187 & 4.8006 & 0.1770 & 0.1455 & 11.1086 & 0.0096 & $1.99 \times 10^{-4}$ \\
7 & 0.6985 & 0.6375 & 4.8006 & 5.2070 & 0.1455 & 0.1224 & 11.1086 & 0.0096 & $2.29 \times 10^{-4}$ \\
8 & 0.6375 & 0.5969 & 5.2070 & 5.5118 & 0.1224 & 0.1083 & 11.1086 & 0.0096 & $2.51 \times 10^{-4}$ \\
$9^{*}$ & 0.5969 & 0.5055 & 5.5118 & 5.7531 & 0.1083 & 0.0878 & 11.1086 & 0.0096 & $2.68 \times 10^{-4}$ \\
10 & 0.2921 & 0.2870 & 2.9464 & 3.4544 & 0.0991 & 0.0831 & 1.9920 & 0.0096 & $5.48 \times 10^{-4}$ \\
\hline
\end{tabular}

(f)

Figure 3: Continued. 


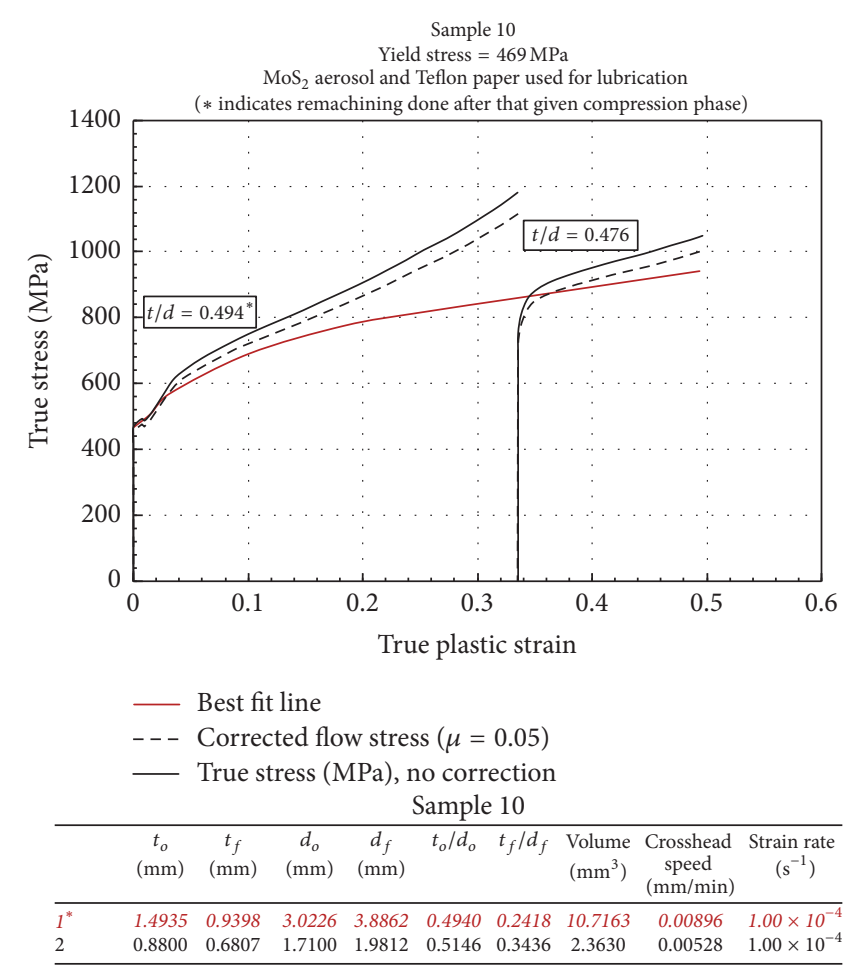

(g)

FIGURE 3: (a) Sample 1 was originally cut by EDM and used dry graphite powder for lubrication. This sample was remachined using a conventional lathe method after phases 1,2 , and 3 (indicated by $*$ next to the individual phase $t / d$ ratios). Lubrication was reapplied between each phase. The average $\dot{\varepsilon}=3.78 \times 10^{-5} \mathrm{~s}^{-1}$. (b) Sample 2 was originally cut by EDM and $\mathrm{MoS}_{2}$ aerosol was used for lubrication. This sample was not remachined after any phases. Lubrication was applied between each phase. The average $\dot{\varepsilon}=3.53 \times 10^{-5} \mathrm{~s}^{-1}$. (c) Sample 3 was originally cut by EDM and $\mathrm{MoS}_{2}$ aerosol was used for lubrication. This sample was ultrasonically remachined after phases 5 and 6 (indicated by $*$ next to the individual phase $t / d$ ratios). Lubrication was reapplied between each phase. The average $\dot{\varepsilon}=5.46 \times 10^{-5} \mathrm{~s}^{-1}$. (d) Sample 4 was originally cut by EDM and $\mathrm{MoS}_{2}$ aerosol was used for lubrication. This sample was ultrasonically remachined after phases 5 and 6 (indicated by $*$ next to the individual phase $t / d$ ratios). Lubrication was reapplied between each phase. The average $\dot{\varepsilon}=5.77 \times 10^{-5} \mathrm{~s}^{-1}$. (e) Sample 7 was originally cut by EDM. MoS 2 aerosol and Teflon paper were used for lubrication. Both faces of the sample were polished to a $0.05 \mu \mathrm{m}$ finish and repolished between each phase. This sample was remachined ultrasonically after phase 5 (indicated by $*$ next to the individual phase $t / d$ ratio). Lubrication was reapplied between each phase. The average $\dot{\varepsilon}=1.11 \times 10^{-4} \mathrm{~s}^{-1}$. (f) Sample 8 was originally cut by EDM and MoS 2 aerosol and Teflon paper were used for lubrication. Both faces of the sample were polished to a $0.05 \mu \mathrm{m}$ finish and repolished between each phase. This sample was remachined ultrasonically after phase 9 (indicated by $*$ next to the individual phase $t / d$ ratio). Lubrication was reapplied between each phase. The average $\dot{\varepsilon}=2.17 \times 10^{-4} \mathrm{~s}^{-1}$. (g) Sample 10 was originally cut by EDM and $\mathrm{MoS}_{2}$ aerosol and Teflon paper were used for lubrication. Both faces of the sample were polished to a $0.05 \mu \mathrm{m}$ finish and repolished between each phase. This sample was remachined ultrasonically after phase 5 (indicated by $*$ next to the individual phase $t / d$ ratio). Lubrication was reapplied between each phase. The average $\dot{\varepsilon}=1.00 \times 10^{-4} \mathrm{~s}^{-1}$. The repolishing of the specimen surface may not have imported the quality of the data over nonsurface polished specimens.

This might be at least partially due to adiabatic heating for the tests greater than $10^{-3} \mathrm{~s}^{-1}$ [7]. One advantage of the current study is that these effects are expected to be absent, while all of the other compression studies referenced, at least at lower purities where stresses are higher, have stress versus strain behaviors that may be influenced by adiabatic heating. Heat would decrease the flow stress of the higher strain-rate test thus only appearing less strong than our thin sheet. The Long et al. curve shifts downward with respect to our thin sheet with strain-rate normalization. We note from Table 3 that the yield stress of the Long et al. study is much higher (530 MPa) than our study (380 MPa average). This might be partly expected based on the reported $\mathrm{m}$ values and the realization that adiabatic heating effect would be minimal at the yield stress. However, we also note from Table 3 that, at strains 0.1 to 0.4 , the stress differences are much less substantial. This loss of apparent strength may actually be due to adiabatic heating. In the absence of this heating, the flow curves might actually be less disparate. However, work by Horiuchi et al. [22] found that in torsion specimens with a low length to diameter ratio (i.e., <1.5) adiabatic heating even at a high rate was not substantial in aluminum (high thermal conductivity). Aluminum has higher thermal conductivity than $\mathrm{Ti}$, and the Horiuchi study had large thermal "sinks" as grips, which may be absent in the Ti compression specimens where lubrication (thermal barriers) may be present. Therefore, in the absence of a very detailed thermal analysis, the effects of adiabatic heating on 


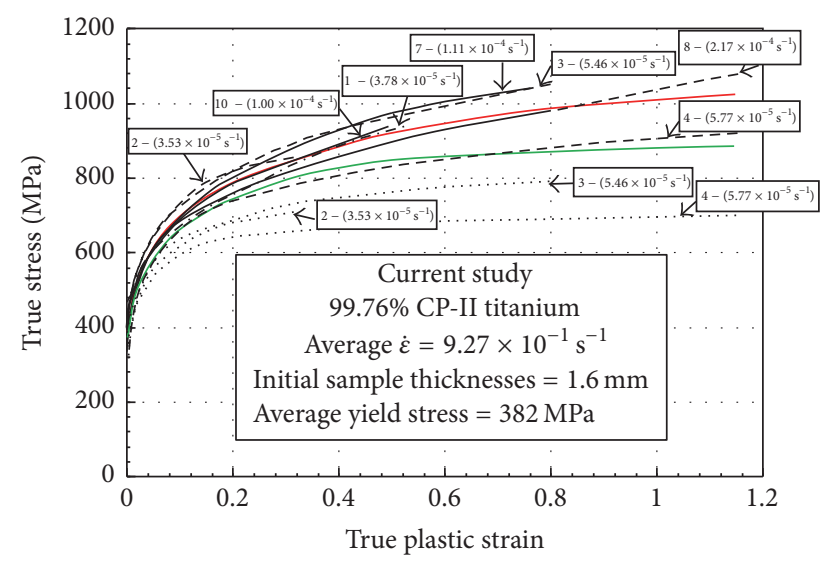

- Average stress (with $\propto=0.03,0.05,0.123$ )

...- Best fit line $(\propto=0.123)$

- - Best fit line $(\propto=0.03)$

B Best fit line $(\propto=0.05)$

..... Best fit line $(\propto=0.23)$

- Average stress (with $\propto=0.05,0.123,0.23$ )

FIGURE 4: The stress versus strain behavior of the tests of this study is averaged into two curves that assume one of the two possible frictional coefficients for $\mathrm{MoS}_{2}$. The average strain rates for each sample are also indicated with $\dot{\varepsilon}=9.27 \times 10^{-5} \mathrm{~s}^{-1}$ as the average for this study.

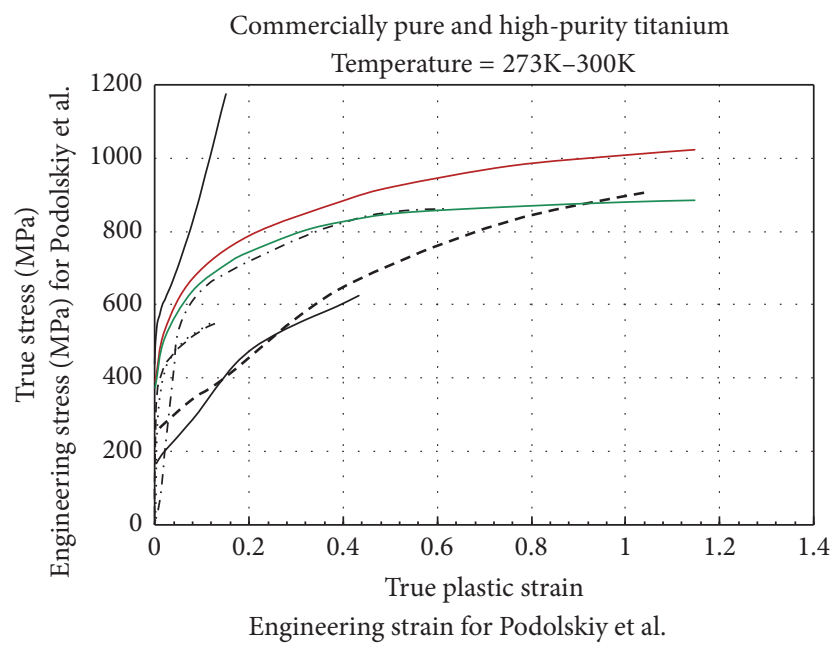

- . - 99.60\% CP-Ti (Long et al.), $t=$ not given, $t / d=1.50$

- 99.52\% CP-II Ti (Podolskiy et al.), $t=35 \mathrm{~mm}, t / d=3.50$

- - - 99.49\% CP-Ti [NR] (Battaini et al.), $t=8 \mathrm{~mm}, t: w: d=0.75$

… 99.49\% CP-Ti [NT] (Battaini et al.), $t=8 \mathrm{~mm}, t: w: d=0.75$

- - - 99.998\% high-purity $\mathrm{Ti}$ (Salem et al.), dimensions not given

- 99.99\% high-purity Ti (Nemat-Nasser et al.), $t=4.8 \mathrm{~mm}$, $t / d=1.00$

- $99.76 \% \mathrm{Ti}$ (current study); $t=1.6 \mathrm{~mm}, t / d=0.52$

- $99.76 \% \mathrm{Ti}$ (current study); $t=1.6 \mathrm{~mm}, t / d=0.52$

Figure 5: The two "average" curves of Figure 4 are compared with the literature values reported earlier in Figure 2.

the flow stress in the Ti compression tests referenced are unclear.

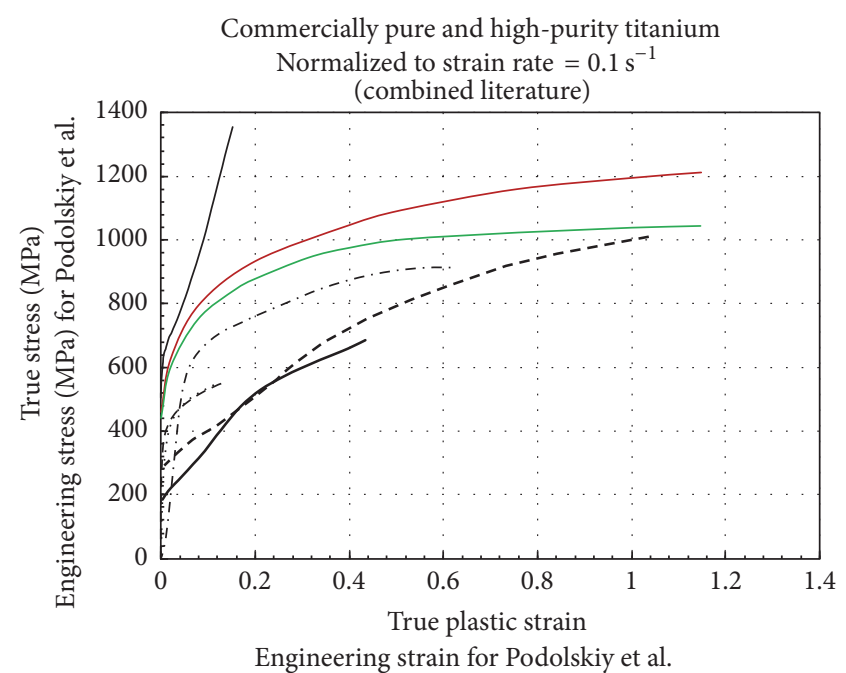

- - $99.60 \%$ CP-Ti (Long et al.), $t=$ not given, $t / d=1.50$

- 99.52\% CP-II Ti (Podolskiy et al.), $t=35 \mathrm{~mm}, t / d=3.50$

- - - 99.49\% CP-Ti [NR] (Battaini et al.), $t=8 \mathrm{~mm}, t: w: d=0.75$

.... 99.49\% CP-Ti [NT] (Battaini et al.), $t=8 \mathrm{~mm}, t: w: d=0.75$

- - - $99.998 \%$ high-purity Ti (Salem et al.), dimensions not given

- $99.99 \%$ high-purity Ti (Nemat-Nasser et al.), $t=4.8 \mathrm{~mm}$, $t / d=1.00$

-99.76\% Ti (current study); $t=1.6 \mathrm{~mm}, t / d=0.52$

$-99.76 \% \mathrm{Ti}$ (current study); $t=1.6 \mathrm{~mm}, t / d=0.52$

FIgURE 6: The stress versus strain curves of the present study and earlier studies all normalized to a strain rate of $10^{-1} \mathrm{~s}^{-1}$ [5] through the average strain-rate sensitivity exponent $m=0.024$ [11, 12, 15-18].

Also, the fact that the sheet of the current study is the thinnest may suggest greater strain in our case through rolling. It appears that the anneal, as a consequence, resulted in a smaller grain size at $14 \mu \mathrm{m}$ (compared with $35 \mu \mathrm{m}$ of the Long et al. study) that leads to a stress increase. The Hall-Petch relationship for Ti [6] suggests that the HallPetch constant of $k_{y}$ be $0.671 \mathrm{MN} / \mathrm{m}^{3 / 2}$; a stress increase with this level of grain size refinement is expected to be about $67 \mathrm{MPa}$. This could explain some of the observed normalized differences (33-67\%) in strength of the thin sheet versus the thicker plate, such as the Long et al. study.

\section{Conclusions}

This study assessed the through-thickness compressive stress versus strain behavior of commercially pure (grade II) $\mathrm{Ti}$ thin sheet to relatively large true strains of about 1.0. The data is unique and is valuable for a variety of applications including Ti sheet metal forming operations. The relatively high strength of the thin sheet revealed through strain-rate normalization may be due to softening by adiabatic heating of higher strain rate tested Ti with which the Ti of this study is compared and/or the refined grain size of the thin titanium sheet of this study resulting from the annealing treatment.

\section{Competing Interests}

The authors declare that they have no competing interests. 
TABLE 3: Tabulated strain rate versus yield stress and flow stress values comparing the present study with two literature sources previously discussed $[2,4]$.

\begin{tabular}{|c|c|c|c|c|c|}
\hline \multirow{2}{*}{ Study } & \multirow{2}{*}{ Strain rate $\left(\dot{\varepsilon}, \mathrm{s}^{-1}\right)$} & \multirow{2}{*}{ Yield stress $\left(\sigma_{y}^{0.2 \%}, \mathrm{MPa}\right)$} & \multicolumn{3}{|c|}{ Flow stress $\left(\sigma_{f}, \mathrm{MPa}\right)$} \\
\hline & & & $10 \%$ strain & $20 \%$ strain & $40 \%$ strain \\
\hline Present study & $9.27 \times 10^{-5}$ & $\begin{array}{c}\mu_{1}, \mu_{2} \\
373,388\end{array}$ & $\begin{array}{c}\mu_{1}, \mu_{2} \\
660,700\end{array}$ & $\begin{array}{c}\mu_{1}, \mu_{2} \\
740,780\end{array}$ & $\begin{array}{c}\mu_{1}, \mu_{2} \\
820,880\end{array}$ \\
\hline Battaini et al. [2] & $1.00 \times 10^{-1}$ & $\begin{array}{l}\text { NT, NR } \\
310,350\end{array}$ & $\begin{array}{l}\text { NT, NR } \\
535,525\end{array}$ & & \\
\hline Long et al. [4] & $1.00 \times 10^{-2}$ & $530 \mathrm{MPa}$ & 640 & 720 & 820 \\
\hline
\end{tabular}

$\mu_{1}$ represents average curve for $\mu=0.05,0.123,0.23$

$\mu_{2}$ represents average curve for $\mu=0.03,0.05,0.123$.

\section{Acknowledgments}

The authors wish to thank nanoPrecision (El Segundo, CA) for providing the material, the metallography, and financial support which they greatly appreciated. They also wish to thank Dr. Matt Gean and Dr. Ann Huang for the many helpful discussions regarding this work.

\section{References}

[1] U. F. Kocks, M. G. Stout, and A. D. Rollett, "The influence of texture on strain hardening," in Proceedings of the Conference on the Strength of Metals and Alloys (ICSMA '88), P. O. Kettunen, T. K. Lepistö, and M. E. Lehtonen, Eds., pp. 25-34, Tampere, Finland, August 1988.

[2] M. Battaini, E. V. Pereloma, and C. H. J. Davies, "Orientation effect on mechanical properties of commercially pure titanium at room temperature," Metallurgical and Materials Transactions A, vol. 38, no. 2, pp. 276-285, 2007.

[3] A. V. Podolskiy, H. P. Ng, I. A. Psaruk, E. D. Tabachnikova, and R. Lapovok, "Equal channel angular pressing at temperatures of 77-575K of titanium grade 2: microstructure and mechanical behavior," IOP Conference Series: Materials Science and Engineering, vol. 63, Article ID 012071, 2014.

[4] F.-W. Long, Q.-W. Jiang, L. Xiao, and X.-W. Li, "Compressive deformation behaviors of coarse- and ultrafine-grained pure titanium at different temperatures: a comparative study," Materials Transactions, vol. 52, no. 8, pp. 1617-1622, 2011.

[5] S. Nemat-Nasser, W. G. Guo, and J. Y. Cheng, "Mechanical properties and deformation mechanisms of a commercially pure titanium," Acta Materialia, vol. 47, no. 13, pp. 3705-3720, 1999.

[6] A. A. Salem, S. R. Kalidindi, and R. D. Doherty, "Strain hardening regimes and microstructure evolution during large strain compression of high purity titanium," Scripta Materialia, vol. 46, no. 6, pp. 419-423, 2002.

[7] R. L. Goetz and S. L. Semiatin, "The adiabatic correction factor for deformation heating during the uniaxial compression test," Journal of Materials Engineering and Performance, vol. 10, no. 6, pp. 710-717, 2001.

[8] W. Schroeder and D. A. Webster, "Press-forging thin sections: effect of friction, area, and thickness on pressures required," Journal of Applied Mechanics, vol. 16, article 289, 1949.

[9] ASTM International, "Standard Test Methods of Compression Testing of Metallic Materials at Room Temperature," Designation: E9-89a (Reapproved 2000), 1-9, 1989.
[10] M. E. Nixon, O. Cazacu, and R. A. Lebensohn, "Anisotropic response of high-purity $\alpha$-titanium: experimental characterization and constitutive modeling," International Journal of Plasticity, vol. 26, no. 4, pp. 516-532, 2010.

[11] A. Akhtar, "Basal slip and twinning in $\alpha$-titanium single crystals," Metallurgical Transactions A, vol. 6, no. 5, pp. 11051113, 1975.

[12] S. V. Kailas, Y. V. R. K. Prasad, and S. K. Biswas, "Influence of initial texture on the microstructural instabilities during compression of commercial $\alpha$-titanium at $25{ }^{\circ} \mathrm{C}$ to $400{ }^{\circ} \mathrm{C}$," Metallurgical and Materials Transactions A, vol. 25, no. 7, pp. 1425-1434, 1994.

[13] B. A. Baumgarten, D. S. Tordonato, and W. F. Kepler, "Investigation of molybdenum disulfide and tungsten disulfide as additives to coating for foul release systems," in Reclamation: Managing Water in the West, pp. 1-14, Materials Engineering and Research Laboratory, Denver, Colo, USA, 2011.

[14] CRC Industries, Dry Moly Lube Technical Data Sheet, Industrial Products Division, Westminster, Pa, USA, 2011.

[15] M. E. Kassner, J. Pollard, E. Evangelista, and E. Cerri, "Restoration mechanisms in large-strain deformation of high purity aluminum at ambient temperature and the determination of the existence of steady-state," Acta Metallurgica et Materialia, vol. 42, no. 9, pp. 3223-3230, 1994.

[16] T.-S. Jun, Z. Zhang, G. Sernicola, F. P. E. Dunne, and T. B. Britton, "Local strain rate sensitivity of single $\alpha$ phase within a dual-phase Ti alloy," Acta Materialia, vol. 107, pp. 298-309, 2016.

[17] D. R. Chichili, K. T. Ramesh, and K. J. Hemker, "The highstrain-rate response of alpha-titanium: experiments, deformation mechanisms and modeling," Acta Materialia, vol. 46, no. 3, pp. 1025-1043, 1998.

[18] M. A. Meyers, G. Subhash, B. K. Kad, and L. Prasad, "Evolution of microstructure and shear-band formation in $\alpha$-hcp titanium," Mechanics of Materials, vol. 17, no. 2-3, pp. 175-193, 1994.

[19] D. Peykov, E. Martin, R. R. Chromik, R. Gauvin, and M. Trudeau, "Evaluation of strain rate sensitivity by constant load nanoindentation," Journal of Materials Science, vol. 47, no. 20, pp. 7189-7200, 2012.

[20] R. E. Reed-Hill, C. V. Iswaran, and M. J. Kaufman, "A power law model for the flow stress and strain-rate sensitivity in $\mathrm{CP}$ titanium," Scripta Metallurgica et Materiala, vol. 33, no. 1, pp. 157-162, 1995.

[21] F. Wang, B. Li, T. T. Gao, P. Huang, K. W. Xu, and T. J. Lu, "Activation volume and strain rate sensitivity in plastic deformation of nanocrystalline Ti," Surface and Coatings Technology, vol. 228, no. 1, pp. S254-S256, 2013. 
[22] R. Horiuchi, J. Kaneko, A. B. Elsebai, and M. M. Sultan, Report No. 443, Institute of Space and Aerospace Science, University of Tokyo, Tokyo, Japan, 1970.

[23] CRC Industries, Dry Graphite Lube Technical Data Sheet, Industrial Products Division, Westminster, Pa, USA, 2013.

[24] Carr Supply Company, More about plastics [M.S. thesis], 2015. 

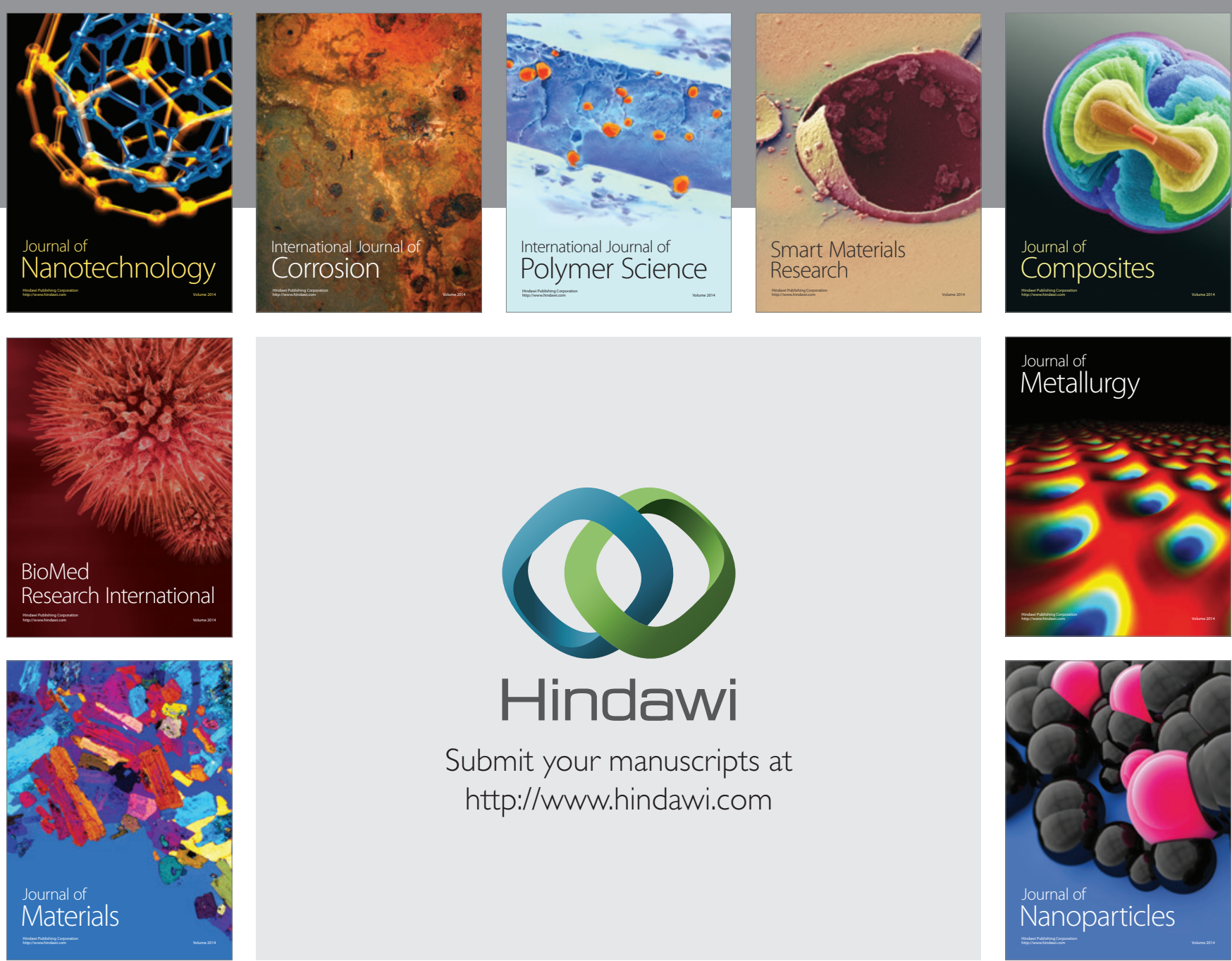

\section{Hindawi}

Submit your manuscripts at

http://www.hindawi.com

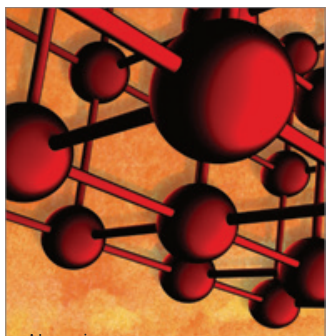

Materials Science and Engineering
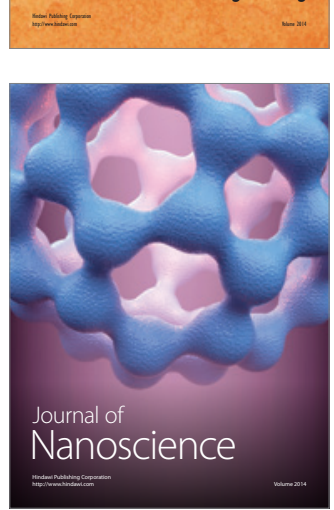
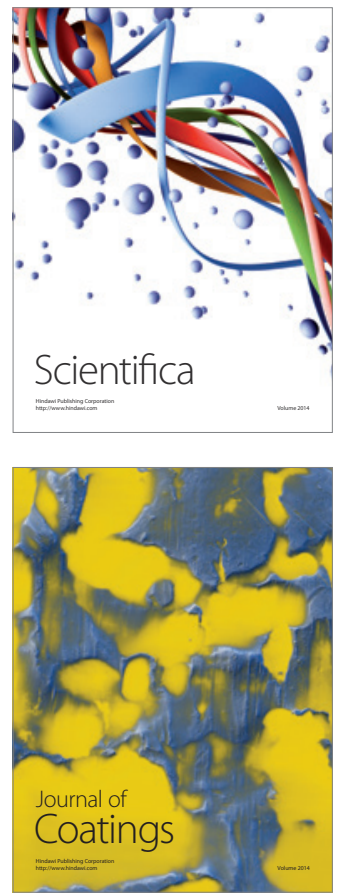
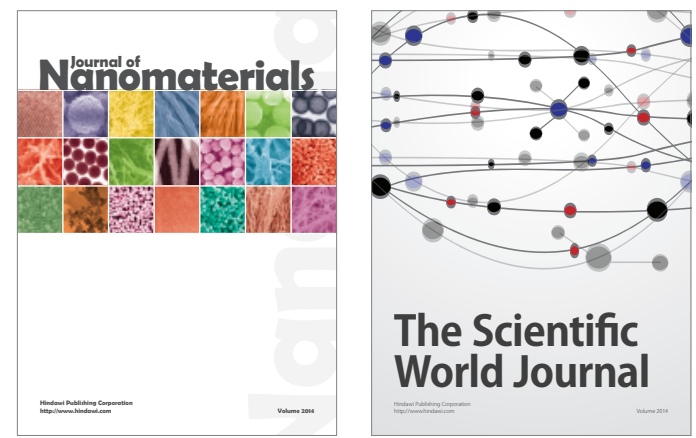

The Scientific World Journal
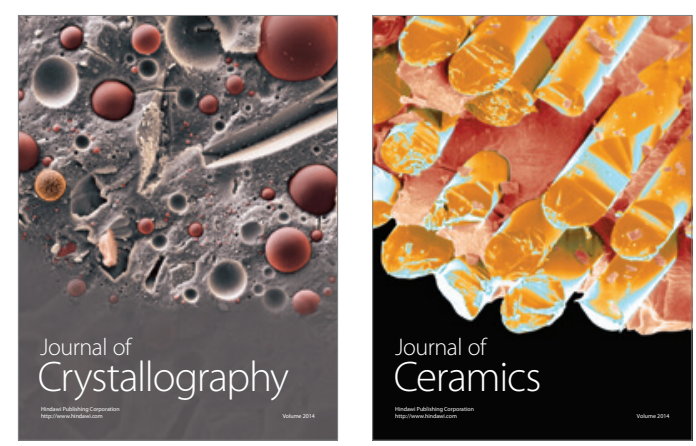
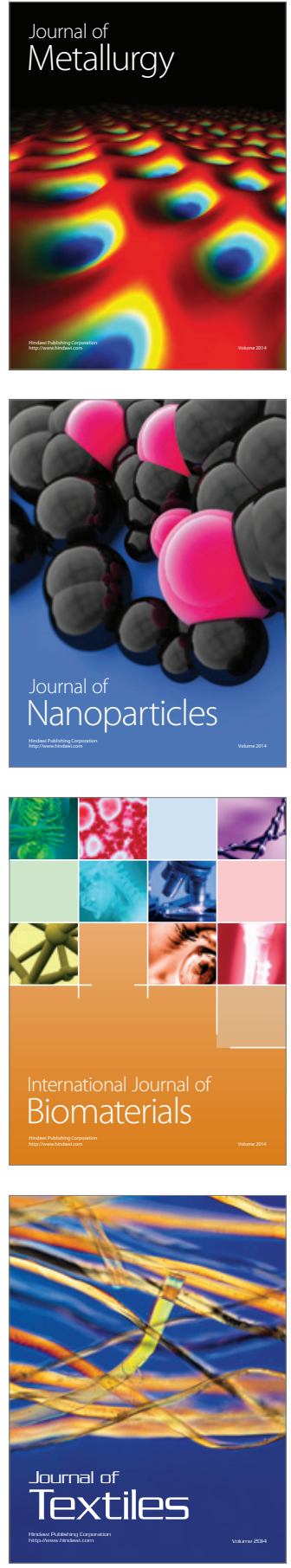